\title{
Beneficial Effects of Calcium Channel Blocker "Nifedipine" on Abnormalities of Platelets and Lipid Metabolism in Patients with Type II Diabetes Mellitus
}

\author{
El-Sayed Emara and Khaled A. Abdel-Sater*
}

Physiology Departments, Tanta Faculty of Medicine and Al-Azhar Faculty of Medicine- Assiut, Egypt

\begin{abstract}
Background and Aim: Platelets play a role in the microvascular as well as macrovascular complications of diabetic patients with serious implications in the pathogenesis of vascular disease in patients with type 2 diabetes. Hyperglycemia changes platelet functions by impairing calcium homeostasis. So, it is important to study the effect of nifedipine on platelet functions and cardiovascular complications associated with diabetes.

Methods: There were 3 groups, i.e. healthy non diabetics (control), type 2 diabetics, and type 2 diabetics with nifedipine therapy (20 in each). For all, the following measurements were done: the cytoplasmic free $\mathrm{Ca}^{2+}$ concentration, platelet aggregation, lipid profiles, arterial blood pressure and heart rate.

Results: Using nifedipine significantly reduced resting and thrombin $(0.5 \mathrm{u} / \mathrm{ml})$ phase 2 platelet cytosolic free calcium in the presence of $(1 \mathrm{mM})$ external calcium compared with the diabetic group. Nifedipine showed no significant change in thrombin induced phase 2 platelet cytosolic free calcium in absence of external calcium compared with the diabetic group. There were no significant differences of peak platelet cytosolic free calcium (thrombin $0.5 \mathrm{u} / \mathrm{ml}$ ) induced in the presence of $1 \mathrm{mM}$ external calcium and in the absence of external calcium between all three groups. There was a significant reduction of lipid profiles except HDL in the diabetic group after nifedipine therapy compared with the diabetic group. HDL cholesterol showed significant increase after nifedipine therapy compared with the diabetic group.
\end{abstract}

Conclusion: Nifedipine therapy is useful for patients with diabetes mellitus type 2 from its effects on platelet aggregation, lipid metabolism and cardiovascular functions.

Keywords: Nifedipine; Platelets; Lipid metabolism; Type 2 diabetes mellitus.

\section{Introduction}

The pathophysiology of diabetic micro- and macroangiopathy may be associated with a hypercoaguable state driven by platelet hyperreactivity [1]. This hyperactivity includes increased platelet adhesion, aggregation, thromboxane production, increased plasma levels of platelet-specific proteins, and increase of platelet turnover [2]. This may lead to increased microembolism in the capillaries and local progression of pre-existing vascular lesions [3]. In diabetes, a vicious cycle is set up in which vascular disease may lead to platelet damage, and altered platelet function may contribute to vascular disease. The loss of sensitivity to the normal restraints generated by the vascular endothelium is the major defect in platelet function [4].

Several mechanisms have been proposed to contribute to the increased platelet reactivity caused by diabetes including the following: a) non-enzymatic glycation of platelet membrane proteins that decreases membrane fluidity, which may increase platelet adhesion; [5] b) osmotic effect of glucose that activates platelet adhesion molecules e.g. glycoprotein complex IIb/IIIa and P-selectin; [6] c) activation of protein kinase $\mathrm{C}$, a mediator of platelet activation; [7] d) glycation of circulating low-density lipoproteins (LDL) which increases calcium -ATPase activity and intracellular calcium concentration [3] and e) impairment in platelet signaling such as nitric oxide $(\mathrm{NO})$ production [8].

Calcium channel blockers work by blocking voltage-gated calcium channels in muscle cells of the heart and blood vessels. Nifedipine prevents calcium levels from increasing as much in the cells when stimulated, leading to less muscle contraction. In the heart, a decrease in calcium available for each beat results in a decrease in cardiac contractility. In blood vessels, a decrease in calcium results in less contraction of the vascular smooth muscle and therefore vasodilation. Vasodilation decreases total peripheral resistance, while a decrease in cardiac contractility decreases cardiac output. Since blood pressure is in part determined by cardiac output and peripheral resistance, blood pressure drops [9]. With a relatively low blood pressure, the after load on the heart decreases. This decreases the amount of oxygen required by the heart. This can help ameliorate symptoms of ischemic heart disease such as angina pectoris [10].

Calcium is required in platelets for many functions such as shape change, secretion, aggregation, and thromboxane formation [6]. Hyperglycemia changes platelet function by impairing calcium homeostasis and thereby alters aspects of platelet activation and aggregation, including platelet conformation and release of mediators [11]. The aim of this work was to determine platelet function in type 2 diabetes and to assess the effect of calcium channel blocker (nifedipine) on platelet functions and cardiovascular complications associated with diabetes.

*Corresponding author: Khaled A. Abdel-Sater Eliwa, Department of Physiology, Faculty of Medicine, Al-Azhar University- Egypt, King Abdul Aziz UniversityRabigh, KSA, Tel: In Egypt +20167970804; In KSA +966-502470699; E-mail: Khaled_71111@yahoo.com, keliwa@kau.edu.sa

Received July 01, 2011; Accepted August 02, 2011; Published August 15, 2011

Citation: Emara E, Abdel-Sater KA (2011) Beneficial Effects of Calcium Channe Blocker "Nifedipine" on Abnormalities of Platelets and Lipid Metabolism in Patients with Type II Diabetes Mellitus. J Diabetes Metab 2:131. doi:10.4172/21556156.1000131

Copyright: (C) 2011 Emara E, et al. This is an open-access article distributed unde the terms of the Creative Commons Attribution License, which permits unrestricted use, distribution, and reproduction in any medium, provided the original author and source are credited. 


\section{Subjects and Methods}

\section{Study design}

A total of a well matched-age (between 25-45years), sex (males), general health and medication (no other medications for other diseases) 40 type 2 diabetics and 20 non-diabetics were selected for this study. There were 3 groups: A control group composed of non diabetic non hypertensive persons with glycosylated hemoglobin (HbA1c) levels in the normal range (3.4-5.4\%), the second group included 20 type 2 diabetic patients, and the third group included 20 diabetic patients after nifedipine administration ( $40 \mathrm{mg}$ once daily for 4 weeks). Diabetic patients were obtained from the diabetic clinic, department of medicine, Tanta university hospital. Informed written consent was obtained from every study subject. HbAlc was used as an index of the metabolic control. No participants had taken any anti platelet or lipid -lowering drugs in the previous two weeks.

Body mass indices, body temperature, heart rate, systolic (SBP) and diastolic blood pressure (DBP) were measured. All anthropometric measurements and blood sampling were conducted in a temperaturecontrolled room maintained at $22 \pm 2^{\circ} \mathrm{C}$. Heart rate was measured centrally and peripherally. Blood pressure was measured after at least 5 min of rest, with a monitor sphygmomanometer with the optimal cuffsize for the subjects' arm circumferences. The first and fifth Korotkoff sounds were recorded to determine the SBP and DBP, respectively. Three blood pressure measurements will be taken and the mean of the last two measurements were used in the analysis [12].

\section{Biochemical measurements}

Determination of blood glucose level: Venous blood samples were obtained under conditions of metabolic stability after at least 8 hours of fasting. Diabetes mellitus was defined as a fasting blood glucose level of $\geq 126 \mathrm{mg} / \mathrm{dL}$ [13]. The blood glucose level was done by glucose oxidase method [14].

Hemoglobin A1C measurements: It was measured by enzymatic calorimetric method using commercial kit [15].

\section{Platelet function tests}

Platelet isolation: Blood samples for platelet function assays were collected from an antecubital vein. The first 2 to $4 \mathrm{ml}$ of blood was discarded to avoid spontaneous platelet activation. Venous blood was drawn into vacutainer tubes containing acid-citrate-dextrose ( $0.8 \%$ citric acid, $2.2 \%$ sodium citrate, and $2.45 \%$ dextrose; $6: 1 \mathrm{vol} /$ vol). Platelet function tests were performed in within $2 \mathrm{~h}$ after blood collection. Platelet-rich plasma (PRP) was obtained by centrifugation at $600 \mathrm{rpm}$ for $15 \mathrm{~min}$ at $18^{\circ} \mathrm{C}$ and was then centrifuged at 2,000 rpm for $15 \mathrm{~min}$ at $18^{\circ} \mathrm{C}$. The supernatant (platelet-poor plasma $=$ PPP) was aspirated, leaving the sedimented pellets which were re-suspended in $500 \mathrm{ml}$ of plasma and then loaded with fluorescent dyes [11].

Measurement of platelet free $\mathrm{Ca}^{2+}$ concentration [16]: The cytoplasmic free $\mathrm{Ca}^{2+}$ concentration $\left[\mathrm{Ca}^{2+}\right]$ i of platelets was determined by $\mathrm{Ca}^{2+}$-sensitive fluorescent indicators. Platelet $\left[\mathrm{Ca}^{2+}\right] \mathrm{i}$ was measured by use of the resultant PRP. The PRP was incubated with 3 fimolfh fura2 -acetoxymethyl ester "fura-2AM- Molecular Probes, Eugene" (diluted in $0.02 \%$ pluronic in anhydrous dimethyl sulfoxide) at $37^{\circ} \mathrm{C}$ for 30 minutes. Extraneous dye was removed by washing the loaded platelets in a buffer containing $(\mathrm{mmol} / \mathrm{L}) \mathrm{NaCl}, 145 ; \mathrm{KC} 1,5 ; \mathrm{MgSO}_{4}, 1 ; \mathrm{Na}_{2} \mathrm{HPO}_{4}$, 0.5; glucose, 5; and HEPES (4-(2-hydroxyethyl)-1-piperazine ethane sulfonic acid), $10, \mathrm{pH} 7.4$ at $25^{\circ} \mathrm{C}$. The platelets were washed twice by centrifugation at $450 \mathrm{~g}$ for 10 minutes at $25^{\circ} \mathrm{C}$ and then were diluted to 1 to $2 \times 10^{8}$ cells per milliliter in the HEPES buffer. Extracellular calcium was adjusted with $1 \mathrm{mmol} / \mathrm{L} \mathrm{CaCl}$. The platelets were stirred continuously with a magnetic stirrer at $1000 \mathrm{rpm}$ in thermostated $\left(37^{\circ} \mathrm{C}\right) 1-\mathrm{mL}$ cuvettes. After the cells were prewarmed at $37^{\circ} \mathrm{C}$ for 10 minutes, fluorescence was recorded at an emission wavelength of 510 $\mathrm{nm}$, and excitation wavelengths of 340 and $380 \mathrm{~nm}$ were recorded on a dual excitation wavelength fluorometer. Maximum $\left[\mathrm{Ca}^{2+}\right]$ i was achieved by addition of Triton X-100 $\left(\mathrm{C}_{14} \mathrm{H}_{22} \mathrm{O}\left(\mathrm{C}_{2} \mathrm{H}_{4} \mathrm{O}\right)\right.$ ) (final concentration of $0.1 \%$ ). This corresponded to complete complexation of fura 2 with $\mathrm{Ca}^{2+}$. Minimal $\left[\mathrm{Ca}^{2+}\right] \mathrm{i}$ was obtained in the presence of EGTA (ethylene glycol tetraacetic acid) (final concentration, $3 \mathrm{mmol} / \mathrm{L}$ ). $\left[\mathrm{Ca}^{2+}\right] \mathrm{i}$ was calculated according to the formula of [17]. $\left.\mathrm{Ca}^{2+}\right] \mathrm{i}=\mathrm{Kd}(\mathrm{R}-\mathrm{Rmin} / \mathrm{Rmax}-\mathrm{R}) \mathrm{b}$ where Kd represented the dissociation constant of fura 2 for $\mathrm{Ca}^{2+}$ taken as $224 \mathrm{nmol} / \mathrm{L}$ at $37^{\circ} \mathrm{C}$, and where $\mathrm{R}$ was the ratio of fluorescence of the sample at 340 and $380 \mathrm{~nm}$; and Rmax and Rmin were the ratios for fura 2 -free acid at these wavelengths in the presence of saturating $\mathrm{Ca}^{2+}$ (with Triton X-100) and EGTA, respectively. b was the ratio of fluorescence at $380 \mathrm{~nm}$ in the presence of EGTA to the fluorescence at $380 \mathrm{~nm}$ in the presence of Triton X-100.

Assessment of platelet aggregation [18]: Aggregation was assessed in siliconized tubes at $37^{\circ} \mathrm{C}$ in constant stirring conditions. Platelet aggregation was determined as the maximal percent change in light transmittance from baseline using PPP as a reference. Pipette $0.45 \mathrm{ml}$ of PRP and $0.45 \mathrm{ml}$ of PPP into different cuvettes and the specimens were incubated at $37^{\circ} \mathrm{C}$ for 5 minutes. The PPP specimen were inserted into the appropriate channel and set instrument to $100 \%$. The tube containing PRP was placed in the aggregometer cuvette and basal (resting) platelet aggregation was measured. Platelet aggregation induced by adding thrombin as an agonist was also measured. A light beam passing through the PRP was measured and as platelets aggregate, more light passed. This determined the percentage of aggregation.

Lipid profiles measurements: Serum total cholesterol, triglyceride, HDL (high density lipoprotein) and LDL were measured by enzymatic calorimetric method using commercial kits $[19,20]$.

\section{Statistical analysis}

It was done using the computer program (prism). The quantitative data were presented in the form of mean \pm standard error (S.E). One way analysis of variance (ANOVA) was done to compare between the studied groups, followed by Students t-test to compare between each two means. Also, correlation coefficients were done. A $\mathrm{P}<0.05$ was considered significant for all analyses. All results were shown as mean \pm standard deviation (mean \pm SD). All data were analysed by Statistical Package for Social Science (SPSS) version 13.0 for Windows (2004) (SPSS ${ }^{\circledR}$ Chicago, IL, USA) software program.

\section{Results}

\section{Platelet function tests}

A- Platelet parameters: Platelet count was significantly lower in the diabetic group compared with the control group. There was no significant change of the platelet count in the diabetic group after nifedipine therapy compared with the diabetic group alone.

Mean platelet volume (MPV) was significantly higher in the diabetic group compared with the control group. There was no significant change of the MPV in the diabetic group nifedipine therapy compared with the diabetic group alone (Table 1).

B- Platelet aggregation: Resting and agonist (thrombin $0.5 \mathrm{u} / \mathrm{ml}$ and $1 \mathrm{u} / \mathrm{ml}$ ) platelet aggregation showed significant elevation in the diabetic group compared with control group. There was a significant 
Citation: Emara E, Abdel-Sater KA (2011) Beneficial Effects of Calcium Channel Blocker "Nifedipine" on Abnormalities of Platelets and Lipid Metabolism in Patients with Type II Diabetes Mellitus. J Diabetes Metab 2:131. doi:10.4172/2155-6156.1000131

Page 3 of 6

reduction of resting and agonist (thrombin $0.5 \mathrm{u} / \mathrm{ml}$ and $1 \mathrm{u} / \mathrm{ml}$ ) platelet aggregation after nifedipine therapy compared with the diabetic group (Table 2).

\section{Platelet $\mathrm{Ca}^{2+}$ homeostasis in normal and diabetic subjects}

The resting platelet $\left[\mathrm{Ca}^{2+}\right] \mathrm{i}$ in a diabetic group was higher $(110.15 \pm 13.30)$ than in nondiabetic control group (27.10 \pm 6.02$)$. This difference was statistically significant $(\mathrm{P}<0.05)$ in an unpaired twosided $t$-test. In the presence of $1 \mathrm{mM}$ extracellular $\mathrm{Ca}^{2+}$, the addition of thrombin $(0.5$ and $1.0 \mathrm{U} / \mathrm{ml})$ increased $\left[\mathrm{Ca}^{2+}\right] \mathrm{i}$ in platelets from all study groups. The typical thrombin response was divided into two phases (Table 3): a rapid immediate $\left[\mathrm{Ca}^{2+}\right] \mathrm{i}$ increase after thrombin addition (peak 1) and a sustained $\left[\mathrm{Ca}^{2+}\right]$ i level (phase 2). The obtained data showed a significant increase of thrombin induced phase 2 platelet cytosolic free calcium in absence of external calcium in the diabetic group (162.450 \pm 23.302$)$ compared with control group (72.550 $\pm 12.626)$.

Using of nifedipine significantly reduced resting platelet cytosolic free calcium and phase 2 (plateau) in the presence of $(1 \mathrm{mM})$ external calcium compared with the diabetic group. While, using nifedipine showed no significant change in thrombin induced phase 2 platelet cytosolic free calcium in absence of external calcium compared with the diabetic group. As regard peak 1 in the absence of external calcium, no significant difference was present between all three groups.

Lipid profiles changes: Total cholesterol, triglyceride and LDL were significantly higher in the diabetic group compared with the control group. There was significant reduction of the total cholesterol, triglyceride and LDL in the diabetic group after nifedipine therapy compared with the diabetic group.

HDL showed significant decrease in the diabetic group compared with control group. There was significant elevation of HDL after nifedipine therapy compared with the diabetic group (Table 4).

Hemodynamic changes: Arterial blood pressure was significantly higher in the diabetic group compared with the control group. There was a significant reduction of the arterial blood pressure in the diabetic

\begin{tabular}{|l|l|l|l|}
\hline $\begin{array}{l}\text { Groups } \\
\text { Parameters }\end{array}$ & Control group & Diabetic group & Diabetic group with nifedipine \\
\hline Platelet count (thousand platelets per cubic millimetre) & $268.500 \pm 48.015$ & $229.900 \pm 56.870$ \\
\hline t. test & & 2.319 & $235.850 \pm 55.821$ \\
\hline P. Value & & $0.026^{*}$ & 1.123 \\
\hline MPV (fl femtoliters) & $9.103 \pm 1.676$ & $11.686 \pm 2.230$ \\
\hline t. test & & -4.140 \\
\hline P. Value & & $<0.276$ \\
\hline
\end{tabular}

Table 1: Platelet parameters in all studied groups (Mean \pm SD).

\begin{tabular}{|c|c|c|c|}
\hline \begin{tabular}{|l|} 
Groups \\
Parameters
\end{tabular} & Control group & Diabetic group & Diabetic group with nifedipine \\
\hline Resting platelet aggregation ( \% ) & $19.950 \pm 3.831$ & $35.600 \pm 7.755$ & $29.65 \pm 6.96$ \\
\hline t. test & & -8.091 & 6.536 \\
\hline P. Value & & $P<0.05$ & $P<0.05$ \\
\hline Agonist (Thrombin $0.5 \mathrm{u} / \mathrm{ml}$ ) induced platelet aggregation $(\%)$ & $45.25 \pm 9.17$ & $65.45 \pm 11.00$ & $55.30 \pm 13.86$ \\
\hline t. test & & -6.303 & 6.683 \\
\hline P. Value & & $P<0.05$ & $P<0.05$ \\
\hline Agonist (Thrombin $1 \mathrm{u} / \mathrm{ml}$ ) induced platelet aggregation (\%) & $68.45 \pm 10.11$ & $76.05 \pm 10.99$ & $68.60 \pm 9.86$ \\
\hline t. test & & -2.275 & 4.967 \\
\hline P. Value & & $P<0.029$ & $P<0.05$ \\
\hline
\end{tabular}

Table 2: Platelet aggregation (\%) in all studied groups (Mean \pm SD).

\begin{tabular}{|c|c|c|c|}
\hline $\begin{array}{l}\text { Groups } \\
\text { Parameters }\end{array}$ & Control group & Diabetic group & Diabetic group with nifedipine \\
\hline Resting & $27.10 \pm 6.02$ & $110.15 \pm 13.30$ & $59.65 \pm 7.583$ \\
\hline t. test & & 22.292 & 16.77 \\
\hline P. Value & & $P<0.05$ & $P<0.05$ \\
\hline Peak $1(n \mathrm{M})$ in the presence of $(1 \mathrm{mM})$ external calcium & $428.650 \pm 106.173$ & $456.950 \pm 114.466$ & $448.500 \pm 103.977$ \\
\hline t. test & & -0.722 & 1.101 \\
\hline P. Value & & $P>0.475$ & $P>0.285$ \\
\hline Phase 2 in the presence of external calcium & $290.750 \pm 31.595$ & $874.100 \pm 111.098$ & $600.550 \pm 145.055$ \\
\hline t. test & & 2.586 & 9.018 \\
\hline P. Value & & $P<0.05$ & $P<0.05$ \\
\hline Peak 1 in the absence of external calcium & $252.750 \pm 40.804$ & $258.050 \pm 42.297$ & $254.200 \pm 43.534$ \\
\hline t. test & & -0.403 & 1.980 \\
\hline P. Value & & P 0.689 & P 0.062 \\
\hline Phase 2 in the absence of external calcium & $72.550 \pm 12.626$ & $162.450 \pm 23.302$ & $161.500 \pm 22.441$ \\
\hline t. test & & 15.170 & 0.903 \\
\hline P. Value & & $P<0.05$ & $P>0.378$ \\
\hline
\end{tabular}

Table 3: Platelet cytosolic free calcium $(n M)$ in all studied groups (Mean $\pm S D$ ). 
Citation: Emara E, Abdel-Sater KA (2011) Beneficial Effects of Calcium Channel Blocker "Nifedipine" on Abnormalities of Platelets and Lipid Metabolism in Patients with Type II Diabetes Mellitus. J Diabetes Metab 2:131. doi:10.4172/2155-6156.1000131

Page 4 of 6

\begin{tabular}{|c|c|c|c|}
\hline $\begin{array}{l}\text { Groups } \\
\text { Parameters }\end{array}$ & Control group & Diabetic group & Diabetic group with nifedipine \\
\hline Total cholesterol mg/dl & $175.200 \pm 9.704$ & $223.200 \pm 29.489$ & $195.400 \pm 17.129$ \\
\hline t. test & & 6.914 & 6.479 \\
\hline P. Value & & $P<0.05$ & $P<0.05$ \\
\hline Triglyceride content $\mathrm{mg} / \mathrm{dl}$ & $94.300 \pm 26.766$ & $184.550 \pm 23.170$ & $126.00 \pm 36.040$ \\
\hline t. test & & 11.401 & 7.252 \\
\hline P. Value & & $P<0.05$ & $P<0.05$ \\
\hline LDL mg /dl & $111.850 \pm 10.053$ & $159.200 \pm 31.917$ & $130.750 \pm 15.535$ \\
\hline t. test & & -6.328 & 4.980 \\
\hline P. Value & & $P<0.05$ & $P<0.05$ \\
\hline HDL mg/dl & $43.600 \pm 6.730$ & $27.450 \pm 6.082$ & $36.800 \pm 6.245$ \\
\hline t. test & & 7.961 & 5.089 \\
\hline P. Value & & $P<0.05$ & $P<0.05$ \\
\hline
\end{tabular}

Table 4: Lipid profiles in all studied groups (Mean \pm SD)

\begin{tabular}{|l|l|l|l|}
\hline $\begin{array}{l}\text { Groups } \\
\text { Parameters }\end{array}$ & Control group & Diabetic group & Diabetic group with nifedipine \\
\hline Systolic blood pressure “mmHg" & $113.25 \pm 16.957$ & $134.00 \pm 19.973$ & $120.50 \pm 14.225$ \\
\hline t. test & & -3.542 & 3.857 \\
\hline P. Value & & $\mathrm{P}<0.05$ & $\mathrm{P}<0.05$ \\
\hline Diastolic blood pressure "mmHg" & $73.250 \pm 11.035$ & $87.000 \pm 12.182$ & $77.750 \pm 9.662$ \\
\hline t. test & & -3.741 & 5.663 \\
\hline P. Value & & $\mathrm{P}<0.05$ & $\mathrm{P}<0.05$ \\
\hline Heart rate (beat/minute): & $77.700 \pm 11.466$ & $79.600 \pm 11.268$ & $86.750 \pm 8.302$ \\
\hline t. test & & -.529 & -4.530 \\
\hline P. Value & & $\mathrm{P}>0.600$ & $\mathrm{P}<0.05$ \\
\hline
\end{tabular}

Table 5: Hemodynamic changes in all studied groups (Mean $\pm S D$ ).

group after nifedipine therapy compared with the diabetic group alone.

There were no significant changes in the heart rate between the diabetic and control groups. However, there was a significant increase of the heart rate in the diabetic group after nifedipine therapy compared with the diabetic group (Table 5).

\section{Discussion}

In the present study, the platelet count in diabetic patients is significantly lower than control non diabetic group and no significant change with nifedipine therapy. These results were in agreement with finding of [21].

Data of the present study revealed a significant increase in the MPV in diabetic group as compared with control group and no significant change with nifedipine therapy. The same was mentioned by [21-23].

In the present study, resting platelet aggregation (\%) was significantly higher in diabetic group compared with control group and significant reduction with nifedipine therapy. Agonist induced platelet aggregation was also significantly higher in diabetic group compared with healthy control group and significant reduction after administration of nifedipine. These results were in agreement with finding of [24].

The first mechanism explaining increased platelet reactivity is increased MPV. The second mechanism explaining increased platelet reactivity could be due to reduced production of factors that inhibit platelet activation, in particular NO. [25]. In platelets from diabetic patients, platelet NO. synthases (NOS) activity is significantly lower than that measured in platelets from healthy subjects which leads to reduced platelet activation, suggesting that the decreased NOS activity might play a role in the pathogenesis of diabetic vascular complications [8]. NO inhibits platelet activation and aggregation by increased cytoplasmic cGMP [26]. Excessive production of reactive oxygen species (ROS) represents the third mechanism explaining increased platelet reactivity in diabetes mellitus [27]. ROS inhibit protein tyrosine phosphatases (PTP), increase cytosolic $\mathrm{Ca}^{2+}$ levels and activate protein tyrosine kinase (PTK) which lead to activation of $\mathrm{Ca}^{2+}$ influx and synthesis of thromboxane $\mathrm{A}_{2}\left(\mathrm{TxA}_{2}\right)$. ROS inactivate the inhibitory NO/cGMP pathway [28]. Nifedipine significantly reduces platelet aggregation. These results were also compatible with John et al. [29] who reported that significant decrease of platelet aggregation and platelet intracellular calcium is achieved by calcium channel blocker administration. He also, reported increased NO. production after administration of calcium channel blocker.

Data of the present study revealed a significant increase of basal $\left[\mathrm{Ca}^{2+}\right] \mathrm{i}$ compared with platelets from healthy control subjects. In the diabetic group administration of nifidipine reduce the basal $\left[\mathrm{Ca}^{2+}\right] \mathrm{i}$ significantly increase compared with diabetic group These results are in agreement with finding of [30-32,11].

Diabetic patients have reduced $\mathrm{Na}+\mathrm{K}+\mathrm{ATP}$ ase activity resulting in elevated intracellular $\mathrm{Ca}^{2+}$ concentration and platelet hyperactivity. Hyperglycemia is associated with increased PKC activity [11], and superoxide anion production as well as reduced antioxidant (glutathione) levels and NOS activity [33].

Data in this study revealed that no significant difference in the peak 1 of the $0.5 \mathrm{U} / \mathrm{ml}$ thrombin-evoked cytosolic $\mathrm{Ca}^{2+}$ transient between platelets from the diabetic and non diabetic groups. Nifedipine therapy caused insignificant change compared with diabetic group. Phase 2 of the thrombin-stimulated $\left[\mathrm{Ca}^{2+}\right]_{\mathrm{i}}$ response was greater in diabetic group compared with control group. Phase 2 platelet cytosolic free calcium was significantly reduced after administration of nifedipine compared with diabetic group. The thrombin-induced initial and transient $\left[\mathrm{Ca}^{2+}\right]$ 
spike (peak 1) reflects the discharge of $\mathrm{Ca}^{2+}$ from intracellular stores such as the DTS, whereas the sustained plateau (phase 2) reflects $\mathrm{Ca}^{2+}$ transport across the plasma membrane. These results are in agreement with finding of Li et al. and Dai $\mathrm{H}$ et al. [11,34].

The peak platelet cytosolic free calcium showed no significant change in diabetic group compared with healthy controls and no significant change in diabetic group compared with diabetic group with nifedipine. This suggested that, in platelets from diabetic subjects, the amount of releasable $\mathrm{Ca}^{2+}$ in the intracellular $\mathrm{Ca}^{2+}$ store was not different from that of normal subjects, so indicating that thrombinreleasable $\mathrm{Ca}^{2+}$ in the DTS is also not changed in diabetes. Phase 2 platelet free calcium in the absence of external calcium showed significant increase in diabetic group compared with healthy controls and no significant change after administration of nifedipine compared with diabetic group. Fall of phase 2 platelet cytosolic free calcium indicated either removal of $\mathrm{Ca}^{2+}$ from the cytosol into internal stores or the extrusion of $\mathrm{Ca}^{2+}$ across the plasma membrane. This result thus indicated that the rate of $\mathrm{Ca}^{2+}$ removal was slower and the extrusion and/or sequestration mechanisms were impaired. There were two mechanisms for $\mathrm{Ca}^{2+}$ extrusion in platelets: $\mathrm{Ca}^{2+}$-ATPase and the $\mathrm{Na}^{+} /$ $\mathrm{Ca}^{2+}$ exchanger.The same was recorded by Li et al. [11].

There were two mechanisms for $\mathrm{Ca}^{2+}$ extrusion in platelets: $\mathrm{Ca}^{2+}-$ ATPase and the $\mathrm{Na}^{+} / \mathrm{Ca}^{2+}$ exchanger. In the DTS, $\mathrm{Ca}^{2+}$ pumps moved $\mathrm{Ca}^{2+}$ against its concentration gradient, and saturation may limit the uptake by this compartment despite increased $\left[\mathrm{Ca}^{2+}\right]_{\text {in }}$ in diabetes. Cytosolic $\mathrm{Ca}^{2+}$ extrusion by the plasma membrane $\mathrm{Ca}^{2+}$-ATPase and the $\mathrm{Na}^{+} / \mathrm{Ca}^{2+}$ exchanger was necessary for maintaining a low $\left[\mathrm{Ca}^{2+}\right]$ in non-diabetics; hence, in diabetes, a problem with one of these pathways will result in increased $\left[\mathrm{Ca}^{2+}\right]_{\mathrm{i}}[30]$. The $\mathrm{Na}^{+} / \mathrm{Ca}^{2+}$ exchanger was a reversible carrier that can mediate the transport of $\mathrm{Ca}^{2+}$ across the plasma membrane in both directions. In most cells and situations the role of the $\mathrm{Na}^{+} / \mathrm{Ca}^{2+}$ exchanger was to remove $\mathrm{Ca}^{2+}$ from the cell (forward mode). However, under some conditions, the exchanger can mediate the net influx of $\mathrm{Ca}^{2+}$ (reverse mode). The net driving force for the exchange was the difference between the membrane potential and the reversal potential of the exchanger. Thus, the activity of the $\mathrm{Na}^{+} /$ $\mathrm{Ca}^{2+}$ exchanger is determined by the $\mathrm{Na}^{+}$gradient, the $\mathrm{Ca}^{2+}$ gradient, and the membrane potential [11].

Diabetes impairs the normal insulin mediated suppression of FFA release from visceral adipose tissue. There was an increased flow of FFA to the liver, which resulted in the overproduction of very low density lipoprotein (VLDL) and led to increased plasma triglycerides. This situation was exacerbated by the reductions in lipoprotein lipase activity and decreases in triglyceride metabolism that occurred in an insulin resistant state. In turn, the increased level of plasma triglycerides causes lowered HDL and increased LDL levels [35]. Moreover, a significant reduction of LDL catabolism was also noted in type 2 diabetic patients. This defect in VLDL and LDL catabolism reflects mainly the reduced activity of lipoprotein lipase, which is in charge of the degradation of triglycerides within VLDL and IDL particles [36].

In this study, administration of nifedipine modified lipid profiles by producing significant reduction of total cholesterol, LDL and triglyceride levels and elevation of HDL. John et al. [29] concluded that nifedipine increases acetyl LDL-mediated cholesterol influx, abolishes the increase in HDL binding induced by cholesterol accumulation, enhances apolipoprotein E synthesis and promotes cholesterol efflux from macrophages. The authors suggest that the nifedipine may increase insulin sensitivity so contributing in protection against atherosclerosis in diabetes. Circulating LDL was protected by the presence of abundant antioxidants in the blood stream.
Type 2 diabetes mellitus is characterized by insulin resistance. Insulin stimulates $\mathrm{NO}$. production from endothelial cells by increasing the activity of NOS via activation of phosphatidylinositol-3 kinase and Akt kinase [8]. Thus, in healthy subjects, insulin increases endotheliumdependent (NO--mediated) vasodilatation. In insulin-resistant subjects, endothelium-dependent vasodilatation is reduced [37].

John et al. [29] observed that the hypotensive effects of calcium channel blockers are mediated primarily by inhibition of calcium flux into smooth muscle cells. Nifedipine increases forearm blood flow with little effect on venous pooling. This indicates selective dilatation of arterial resistance vessels. The decrease in arterial blood pressure elicits sympathetic reflexes with resultant tachycardia and positive inotropy. Nifedipine also has direct negative inotropic effects in vitro. However, nifedipine relaxes vascular smooth muscle at significantly lower concentrations than those required for prominent direct effects on the heart. Thus, arteriolar resistance and blood pressure are lowered, contractility and segmental ventricular function are improved, and heart rate and cardiac output are increased [38].

\section{References}

1. Zbidi H, López J, Nidhal A, Aghleb B, Ginés M et al. (2009) Enhanced expression of STIM1/Orai1 and TRPC3 in platelets from patients with type 2 diabetes mellitus. Blood Cells Mol Dis 43: 211-213.

2. Liu D, Maier A, Scholze A, Rauch U, Boltzen U, et al. (2008) High glucose enhances transient receptor potential channel canonical type 6-dependent calcium influx in human platelets via phosphatidylinositol 3-kinase-dependent pathway. Arterioscler Thromb Vasc Biol 28: 746-751.

3. Aaron R, Nena A, Antonio S, Eric B (2009) Risk factor correlates of platelet and leukocyte markers assessed by flow cytometry in a population-based sample. Atherosclerosis 205: 272-278.

4. Bernd S and Diethelm T (2005) Pathobiology and cell interactions of platelets in diabetes. Diab Vasc Dis Res 2: 16-23.

5. Morel O, Kessler L, Ohlmann P, Bareiss P (2010) Diabetes and the platelet: Toward new therapeutic paradigms for diabetic atherothrombosis. Atherosclerosis 212: 367-376

6. Keating F, Sobel B and Schneider D (2003) Effects of increased concentrations of glucose on platelet reactivity in healthy subjects and in patients with and without diabetes mellitus. Am J Cardiol 92: 1362-1365.

7. Assert R, Scherk G, Bumbure A, Pirags V Schatz H, et al. (2001) Regulation of protein kinase $\mathrm{C}$ by short term hyperglycemia in human platelets in vivo and in vitro. Diabetologia 44: 188-195.

8. Fatini C, Sticchi E, Bolli P, Marcucci R, Giusti B, et al. (2011) Platele aggregability is modulated by eNOS locus in non-type 2 diabetic patients with acute coronary syndrome. Nutr Metab Cardiovasc Dis 21: 11-17.

9. Thompson A, Pope J (2005) Calcium channel blockers for primary Raynaud's phenomenon: a meta-analysis. Rheumatology (Oxford) 44: 145-150.

10. Varon J, Marik P (2003) Clinical review: The management of hypertensive crises. Critical Care (London) 7: 374-384.

11. Li Y, Woo V, Bose $R$ (2001) Platelet hyperactivity and abnormal $\mathrm{Ca}^{2+}$ homeostasis in diabetes mellitus. Am J Physiol Heart Circ Physiol 280 H1480-H1489.

12. Snehalatha C, Ramachandran A, Satyavani S, Sivasankari V (2003) Clustering of cardiovascular risk factors in impaired fasting glucose and impaired glucose tolerance. Int J Diab Dev Countries 23: 59-61.

13. Alberti KG, Zimmet PZ (1998) Definition, diagnosis and classification of diabetes mellitus and its complications. Part 1: Diagnosis and classification of diabetes mellitus provisional report of a WHO consultation. Diabet Med 15 539-553.

14. Young D, Friedman RB (2001) Effects of disease on clinical laboratory tests Washington, DC: AACC Press, 4th Edition, Vol. 1. ISBN 1-890883-45-X

15. Bisse E, Abraham EC (1985) New less temperature-sensitive 
Citation: Emara E, Abdel-Sater KA (2011) Beneficial Effects of Calcium Channel Blocker "Nifedipine" on Abnormalities of Platelets and Lipid Metabolism in Patients with Type II Diabetes Mellitus. J Diabetes Metab 2:131. doi:10.4172/2155-6156.1000131

microchromatographic method for the separation and quantitation of glycosylated hemoglobins using a non-cyanide buffer system. J Chromatog 344: 81-91.

16. Touyz R, Schiffrin E (1993) Effects of angiotensin II and endothelin-1 on platelet aggregation and cytosolic $\mathrm{pH}$ and free $\mathrm{Ca}^{2+}$ concentrations in essential hypertension. Hypertension 22: 853-862.

17. Grynkiewicz G, Poenie M, Tsien R (1985) A new generation of $\mathrm{Ca}^{2+}$ indicators with greatly improved fluorescence properties. J Biol Chem 260: 3440-3450.

18. Angiolillo DJ, Fernandez-Ortiz A, Bernardo E, Ramirez C, Barrera-Ramirez C, et al. (2005) Identification of low responders to a $300 \mathrm{mg}$ clopidogrel loading dose in patients undergoing coronary stenting. Thromb Res 115: 101-108.

19. Friedewald W, Levy R, Fredrickson D (1972) Estimation of the concentration of low-density lipoprotein cholesterol in plasma, without use of the preparative ultracentrifuge. Clin Chem 18: 499-502.

20. Widhaim K, Pakosta R (1991) Precipitation with polyethylene glycol and high gradient ultracenrifugation compared for determining High Denisty lipoprotein Subclasses HDL2 and HDL3. Clin Chem 37: 238-240.

21. Hekimsoy Z, Payzin B, Ornek T, Kandoğan G (2004) Mean platelet volume in type 2 diabetic patients. J Diabetes Complications 18: 173-176.

22. Papanas N, Symeonidis G, Maltezos E (2004) Mean platelet volume in patients with type 2 diabetes mellitus. Platelets 15: 475-478.

23. Boos CJ, Lip GY (2007) Assessment of mean platelet volume in coronary artery disease - what does it mean? Thromb Res 120: 11-13.

24. Vericel E, Januel C, Carreras M, Moulin P, Lagarde M (2004) Diabetic patients without vascular complications display enhanced basal platelet activation and decreased antioxidant status. Diabetes 53: 1046-1051.

25. Queen LR, Ji Y, Goubareva I, Ferro A (2003) Nitric oxide generation mediated by -adrenoceptors is impaired in platelets from patients with type II diabetes mellitus. Diabetologia 46: 1474-1482.

26. Schafer A, Wiesmann F, Neubauer S, Eigenthaler M, Bauersachs J, Channon $\mathrm{K}$ (2004) Rapid regulation of platelet activation in vivo by nitric oxide. Circulation 109: 1819-1822.
27. Varughese G, Tomson J, Lip G (2005) Type 2 diabetes mellitus: A cardiovascular perspective. Int J Clin Pract 59: 798. 816.

28. El Haouari, Rosado J (2008) Platelet signalling abnormalities in patients with type 2 diabetes mellitus: a review. Blood Cells Mol Dis 41: 119-123.

29. Mancini GB (2002) Antiatherosclerotic effects of calcium channel blockers Prog cardiovasc dis 45: $1-20$

30. Mazzanti L, Rabini R, Faloia E, Fumelli P, Bertoli E et al. (1990): Altered cellula $\mathrm{Ca}^{2+}$ and $\mathrm{Na}^{+}$transport in diabetes mellitus. Diabetes 39: 850-854.

31. Tschope D, Roesen P, Gries FA (1991) Increase in the cytosolic concentration of calcium in platelets of diabetes type 2.Thromb Res 62: 421-428.

32. Yamaguchi T, Kadono K, Tetsutani T, Yasunaga K (1991) Platelet-free $\mathrm{Ca}^{2+}$ concentration in noninsulin-dependent diabetes mellitus. Diabetes Res Clin 18 89-94.

33. Mazzanti L, Mutus B (1997) Diabetes induced alterations in platelet metabolism. Clin Biochem 30: 509-515.

34. Dai H, Chen J, Tao Q, Zhu J, Zheng L et al. (2003) Effect of diltiazem on platele activation and cytosolic calcium during percutaneous transluminal coronary angioplasty. Postgrad Med J 79: 522-526.

35. Carmena R (2005) Type 2 diabetes, dyslipidemia, and vascular risk: Rationale and evidence for correcting the lipid imbalance. Am Heart J150: 859-870.

36. Vergès $B$ (2005) New insight into the pathophysiology of lipid abnormalities in type 2 diabetes. Diabetes Metab 31: 429-443.

37. Mather K, Laakso M, Edelman S, Hook G, Baron A (2000) Evidence for physiological coupling of insulin-mediated glucose metabolism and limb blood flow. Am J Physiol Endocrinol Metab 279: E1264-E1270.

38. David M, Rose M, David R (2001) Drugs used for the treatment of myocardial ischemia: in Goodman and Gilman's. The pharmacological basis of therapeutics, $10^{\text {th }}$ ed., chap. 32: $853-860$.

39. Watala C, Golański J, Boncler MA, Pietrucha T, Gwoździński K (1998) Membrane lipid fluidity of blood platelets: a common denominator that underlies the opposing actions of various agents that affect platelet activation in whole blood. Platelets 9: 315-327. 